\title{
Long-term efficacy and safety of subcutaneous C1-inhibitor in women with hereditary angioedema: subgroup analysis from an open-label extension of a phase 3 trial
}

Donald S. Levy ${ }^{1 *} \mathbb{C}$, Henriette Farkas ${ }^{2}$, Marc A. Riedl $^{3}$, Florence Ida Hsu ${ }^{4}$, Joel P. Brooks ${ }^{4}$, Marco Cicardi ${ }^{\wedge}$, Henrike Feuersenger ${ }^{6}$, Ingo Pragst ${ }^{6}$ and Avner Reshef ${ }^{7}$

\begin{abstract}
Background: Women with hereditary angioedema due to C1-inhibitor deficiency (HAE-C1INH) experience more frequent and severe angioedema attacks compared with men. Fluctuations in female sex hormones can influence HAE attack frequency and severity. Subcutaneous C1-INH (C1-INH [SC]) is indicated as routine prophylaxis to prevent HAE attacks. In this post hoc subgroup analysis, we evaluated the efficacy and safety of C1-INH (SC) in female subjects with HAE-C1INH enrolled in an open-label extension of the pivotal phase III COMPACT trial.

Methods: In this multicenter, randomized, parallel-arm trial, eligible subjects (age $\geq 6$ years with $\geq 4$ attacks over 2 consecutive months) received C1-INH (SC) $40 \mathrm{IU} / \mathrm{kg}$ or $60 \mathrm{IU} / \mathrm{kg}$ twice weekly for 52 to 140 weeks. Analyses of efficacy endpoints were performed for all female subjects and those of childbearing age (age $\geq 15$ to $\leq 45$ years), including subjects who became pregnant during the evaluation period.

Results: Overall, 91\% (69/76) of female subjects were classified as responders ( $\geq 50 \%$ reduction in HAE attacks relative to the pre-study period); $82 \%$ experienced $<1$ attack/4 weeks. The median number of attacks/month was 0.10 , with $96 \%$ median reduction in attacks relative to the pre-study period. Results were similar in the subgroup of subjects of childbearing age. Four women who became pregnant during the trial and were exposed to C1-INH (SC) during the first trimester delivered healthy babies with no congenital abnormalities.
\end{abstract}

Conclusions: $\mathrm{C1}-\mathrm{INH}(\mathrm{SC})$ prophylaxis was safe and effective in women with $\mathrm{HAE}-\mathrm{C} 1 \mathrm{INH}$, including those of childbearing age. Four women exposed to $\mathrm{C} 1-\mathrm{INH}$ (SC) during the first trimester had uneventful pregnancies and delivered healthy babies.

Trial registration Clinicaltrials.gov identifier NCT02316353 (Registered December 10, 2014); https://clinicaltrials.gov/ct2/ show/NCT02316353.

Keywords: Hereditary angioedema, Female, Women, HAEGARDA, Estrogen, C1-inhibitor, Childbearing, Pregnancy, Conception

*Correspondence: Allergymd1@gmail.com

${ }^{\wedge}$ Marco Cicardi-Deceased

1 University of California-Irvine, Orange, 705 W La Veta Avenue, Suite 101, Orange, CA 92868, USA

Full list of author information is available at the end of the article

\section{Background}

Hereditary angioedema (HAE) due to C1-inhibitor (C1-INH) deficiency (HAE-C1INH) is a rare genetic disorder characterized by recurrent, unpredictable, and disabling episodes of edema. Commonly affected sites

(c) The Author(s) 2020. This article is licensed under a Creative Commons Attribution 4.0 International License, which permits use, sharing, adaptation, distribution and reproduction in any medium or format, as long as you give appropriate credit to the original author(s) and the source, provide a link to the Creative Commons licence, and indicate if changes were made. The images or other third party material in this article are included in the article's Creative Commons licence, unless indicated otherwise in a credit line to the material. If material is not included in the article's Creative Commons licence and your intended use is not permitted by statutory regulation or exceeds the permitted use, you will need to obtain permission directly from the copyright holder. To view a copy of this licence, visit http://creativeco mmons.org/licenses/by/4.0/. The Creative Commons Public Domain Dedication waiver (http://creativecommons.org/publicdomain/ zero/1.0/) applies to the data made available in this article, unless otherwise stated in a credit line to the data. 
include the face, limbs, trunk, and submucosal tissues of the gastrointestinal, genitourinary, and upper respiratory tract. The latter includes potentially life-threatening laryngeal attacks $[1,2]$. Although HAE-C1INH is an autosomal dominant disorder, published series of symptomatic patients demonstrate a slight female predominance (60\%) [2-4].

The HAE-C1INH disease burden is greater in women compared with men; women with HAE-C1INH experience attacks more frequently and their attacks tend to be more severe [2-4]. In a study of 209 patients with HAE-C1INH (female, $\mathrm{n}=127$; male, $\mathrm{n}=82$ ), significantly more women than men $(60.7 \%$ vs $43.6 \% ; P<0.02)$ had $>12$ attacks per year [2]. In a retrospective study of 193 French patients, $34.4 \%$ of attacks reported by women were classified as severe compared with $23.6 \%$ of attacks reported by men [4].

It is not clear why women with HAE are more severely affected than men, but estrogen (endogenous and exogenous) likely plays a role. It is known that natural hormonal fluctuations, such as those occurring during puberty, menses, pregnancy, or menopause, affect the course of HAE and the frequency of HAE symptoms [5]. In a survey of women with HAE-C1INH $(\mathrm{N}=150)$, $62 \%$ reported disease worsening during puberty and $32 \%$ reported worsening during menopause; 35\% reported that attacks were triggered by menstruation and $14 \%$ by ovulation [5]. Bork et al. also reported that menstruation and ovulation may trigger skin swelling and abdominal pain [2]. In a study by Zotter et al., menstruation, pregnancy, estrogen-containing oral contraceptive use, and ovulation were identified as HAE attack triggers by patients with HAE-C1INH [6].

The effect of pregnancy on disease activity among women with HAE-C1INH varies; some women report improvement or no change while others report worsening [7-9]. In a study of 41 women with HAE-C1INH and 118 pregnancies, almost half (48\%) reported worsening of HAE manifestations, while one-third (33\%) reported improvement [7]. Another study of 22 women and 35 pregnancies reported that attack rates increased in $83 \%$ of pregnancies, with the highest rates occurring during the second and third trimesters [8]. A more recent review of 61 patients and 125 pregnancies found that attacks increased in $59.2 \%$ of the pregnancies, improved in $14 \%$, and remained unchanged in $26.4 \%$ [9]. Lactation can also increase the frequency of HAE attacks, particularly abdominal attacks $[2,8,10]$.

The majority of women with HAE-C1INH report increased disease activity with use of estrogen-containing oral contraceptives or hormone replacement therapy (HRT) $[5,11]$. Bork et al. reported that among 32 women with HAE-C1INH, 63\% reported new or worsening symptoms after taking oral contraceptives or HRT [11]. In a retrospective study that included 91 women with HAE-C1INH using contraception, symptoms worsened in $80 \%$ of women taking combined oral contraceptives (47/59 patients), while $64 \%$ of those on progestin-only contraceptives (9/14 patients) reported improvement [5].

The mechanism by which estrogen promotes HAE attacks has not been clearly elucidated. Joseph et al. suggested that interleukin-1 (IL-1), tumor necrosis factor (TNF)-alpha, and estrogen can promote HAE attacks via stimulation of endothelial cells and augmented activation of the prekallikrein-high-molecular-weight kininogen complex (prekallikrein-HMWK) to generate kallikrein and bradykinin [12]. Estrogen has been shown to directly stimulate the local release of heat-shock protein 90 (Hsp90) from endothelial cells, which activates the prekallikrein-HMWK complex to form kallikrein [12]. Kallikrein cleaves from HMWK the nonapeptide bradykinin, a potent inducer of vasodilation and vascular permeability [12]. Activation of vascular endothelial bradykinin B2 receptors is presumed to be the final step in angioedema formation [12, 13]. Therefore, estrogen may also play an important role in regulating bradykinin B2 receptor expression and function [14].

Treatment approaches for HAE-C1INH include on-demand therapy for HAE attacks, short-term prophylaxis, and long-term prophylaxis [15]. The 2017 guideline for managing HAE, issued by the World Allergy Organization (WAO) in collaboration with the European Academy of Allergy and Clinical Immunology (EAACI), recommends that long-term prophylaxis be considered for "patients who face events in life that are associated with increased disease activity [15]." Because HAE tends to be more frequent, severe, and related to hormonal fluctuations in women, many women may benefit from long-term prophylactic therapy, which is intended to lessen the burden of disease, and reduce the frequency and severity of HAE attacks [15].

The 2017 WAO/EAACI guideline recommends plasma-derived (pd) C1-INH as a first-line option for long-term prophylaxis in patients with HAE-C1INH [15]. Subcutaneous C1-INH (C1-INH [SC], HAEGARDA ${ }^{\circledR}$, CSL Behring, Marburg, Germany) has been approved by the US Food and Drug Administration for routine prophylaxis to prevent HAE attacks in adolescents and adults [16]. Indeed, the efficacy and safety of C1-INH (SC) have been demonstrated in the placebo-controlled, phase III COMPACT trial and an open-label extension (OLE) of that trial, in which subjects were treated for up to 2.7 years $[17,18]$.

Women comprised the majority of subjects in the COMPACT (Clinical Study for Optimal Management of Preventing Angioedema with Low-Volume Subcutaneous 
C1-Inhibitor Replacement Therapy) trial (67\%) and the OLE $(60 \%)[17,18]$. In the COMPACT trial, $71 \%$ of subjects $(n=32 / 45)$ randomized to receive the FDAapproved dose of $60 \mathrm{IU} / \mathrm{kg} \mathrm{C} 1-\mathrm{INH}$ (SC) were women (mean age, $35.0 \pm 13.8$ years) $[18,19]$.

An analysis of that subgroup showed a $93 \%$ median reduction in attack rates relative to placebo (median, 4.06 attacks/month with placebo vs 0.29 attacks/month with C1-INH [SC]); 12 of 32 (37.5\%) female subjects were attack free during prophylaxis [19]. In addition, responder analyses showed $89 \%(n=24 / 27)$ had $\geq 50 \%$ reduction in the time-normalized number of HAE attacks relative to placebo and were classified as responders; $82 \%$ $(\mathrm{n}=22)$ had $\geq 70 \%$ reduction in attacks and $52 \%(\mathrm{n}=14)$ had $\geq 90 \%$ reduction in attacks [19].

The purpose of this post hoc analysis was to evaluate the long-term efficacy and safety of C1-INH (SC) in women with HAE-C1INH enrolled in the OLE, with a special focus on women of childbearing age. Women in this age group may become pregnant during prophylactic therapy, underscoring the need for a safe and effective therapy in this population.

\section{Methods}

\section{COMPACT OLE trial description}

The OLE of the COMPACT trial was a multicenter, randomized, parallel-arm trial and included subjects who had completed the COMPACT trial, as well as C1-INH (SC)-naive subjects. Eligible subjects (age $\geq 6$ years with $\geq 4$ attacks over 2 consecutive months before enrollment) were randomly assigned to receive C1-INH (SC) $40 \mathrm{IU} / \mathrm{kg}$ or $60 \mathrm{IU} / \mathrm{kg}$ twice weekly for 52 weeks.
In the United States, subjects were able to continue treatment for 88 additional weeks (Fig. 1) [18].

The OLE study (NCT02316353) on which the present subgroup analysis is based was done in accordance with the standards of Good Clinical Practice as defined by the International Council for Harmonization of Technical Requirements for Registration of Pharmaceuticals for Human Use, ethical principles that have their origin in the Declaration of Helsinki, and applicable national and local regulations. Study Protocol and amendments were approved by independent ethics committees or institutional review boards at all participating centers prior to study commencement. All patients, or their legal guardians, provided written informed consent.

\section{Efficacy analyses}

The primary objective of the OLE was to assess the longterm safety of C1-INH (SC). Efficacy endpoints were the percentage of subjects with $\geq 50 \%$ reduction in attacks relative to the pre-study value (i.e., the number of attacks used to qualify for enrollment into the COMPACT trial or the OLE) and the percentage of subjects with $<1$ attack per 4-week period. Exploratory efficacy endpoints included the time-normalized number of HAE attacks and time-normalized rescue medication use [18].

In the OLE, female subjects of childbearing potential were required to use reliable contraception or be sexually abstinent during the trial. Per study protocol, women who became pregnant during treatment were discontinued from the trial. These subjects were included in the efficacy and safety analyses until they discontinued treatment.

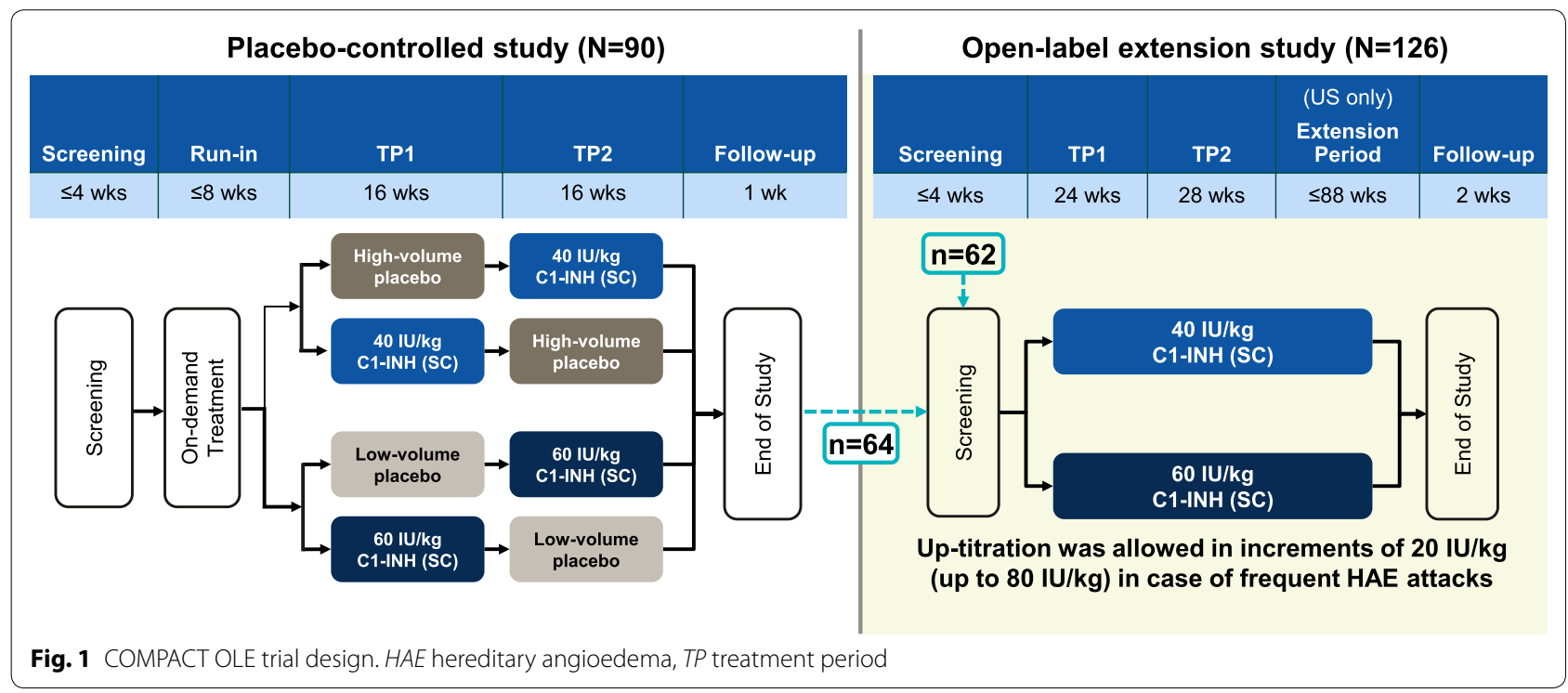


Subgroup analyses of efficacy endpoints were performed for all female subjects and those of childbearing age (age $\geq 15$ to $\leq 45$ years) treated in the OLE, including those who became pregnant during the evaluation period.

Urine samples for pregnancy testing were obtained (1) before randomization and dosing; (2) at weeks 9, 25, 37 , and 53 of the OLE; and (3) at weeks 0 (if applicable), $24,48,72$, and 88 of the additional US extension. Women who became pregnant were followed postdiscontinuation until delivery to assess pregnancy outcomes.

\section{Results}

\section{Baseline demographic characteristics}

Of the 126 subjects treated with C1-INH (SC) in the OLE trial, 76 (60.3\%) were women (mean age, 40.9 years; mean body mass index [BMI], $28.0 \mathrm{~kg} / \mathrm{m}^{2}$ ). Of the 76 female subjects, 42 (55\%) were of childbearing age (mean age, 32.5 years; mean BMI, $27.0 \mathrm{~kg} / \mathrm{m}^{2}$ ) (Table 1 ).

\section{Efficacy outcomes in the female study population}

Key efficacy outcomes in the female study population and females of childbearing age are presented in Table 2. Overall, $91 \%$ of female subjects and 90\% of females of childbearing age were classified as responders to treatment with $\mathrm{C} 1-\mathrm{INH}$ (SC), with $\geq 50 \%$ reduction in attacks relative to the pre-study period. In the overall population (women and men), 93\% of evaluable subjects were responders [18]. In the OLE, $82 \%$ of female subjects overall, $81 \%$ of female subjects of childbearing age, and $83 \%$ of the overall population experienced $<1$ attack per 4-week period with $\mathrm{C} 1$-INH (SC).

During treatment with C1-INH (SC) (40 IU/kg and $60 \mathrm{IU} / \mathrm{kg}$ ), the median number of HAE attacks per month was 0.10 in female subjects overall, with a $96 \%$ median reduction in attacks relative to the pre-study period (Table 3). In female subjects of childbearing age, the median number of attacks per month was 0.16 , with a 95\% median reduction in attacks relative to the pre-study period.

Mean (SD) rescue medication use per month was 0.33 $(0.78)$ in the subpopulation of female subjects and 0.30
Table 2 Secondary efficacy endpoints in female subjects treated long-term with C1-INH (SC)

\begin{tabular}{llll}
\hline & $\begin{array}{l}\text { All female } \\
\text { subjects } \\
(\mathbf{n}=\mathbf{7 6})\end{array}$ & $\begin{array}{l}\text { Females } \\
\text { of childbearing } \\
\text { age }(\mathbf{n}=\mathbf{4 2})\end{array}$ & $\begin{array}{l}\text { Overall study } \\
\text { population } \\
(\mathbf{N = 1 2 6})^{\mathbf{1 8}}\end{array}$ \\
\hline $\begin{array}{l}\text { Response }(\geq 50 \% \\
\text { reduction in } \\
\text { attacks })\end{array}$ & $91 \%(69 / 76)$ & $90 \%(38 / 42)$ & $93 \%(113 / 122)$ \\
$<1$ attack/4 weeks & $82 \%(62 / 76)$ & $81 \%(34 / 42)$ & $83 \%(104 / 126)$ \\
\hline
\end{tabular}

C1-INH (SC) subcutaneous C1-inhibitor

(0.76) among female subjects of childbearing age, similar to that observed in the overall study population (0.29) (0.76) (Table 3).

\section{Outcomes in subjects who became pregnant} during treatment with $\mathrm{C} 1-\mathrm{INH}$ (SC)

Four women became pregnant within 1 year of starting treatment and were discontinued from the trial, as mandated by the study protocol [18]. In these subjects, C1-INH (SC) exposure after the last menstrual period ranged from 4 weeks (9 doses) to 8 weeks (15 doses); 3 subjects had been treated with the $60 \mathrm{IU} / \mathrm{kg}$ dose. Pregnancy was normal in all cases, with no related complications. All 4 women delivered healthy babies (mean weight: $3.1 \mathrm{~kg}$ ) (Table 4), and no congenital abnormalities were reported during the early postnatal hospital discharge.

During active treatment with C1-INH (SC), all 4 subjects were classified as responders, with $\geq 50 \%$ reduction in attacks; all 4 had $<1$ attack per 4 -week period; 1 subject was attack free. Notably, 3 of the 4 subjects reported no use of rescue medication during prophylaxis with $\mathrm{C} 1-\mathrm{INH}$ (SC), and the remaining subject used rescue medication only once over a period of $>40$ weeks of treatment. The 4 women who became pregnant were exposed to C1-INH (SC) for 4 to 8 weeks after their last menstrual period before prophylaxis was discontinued (per study protocol). During this period, 3 subjects had no attacks and 1 experienced a single moderate HAE attack. Immediately after discontinuing C1-INH (SC) prophylaxis, 2 of the 4 subjects reported a

Table 1 Demographic characteristics of female subjects treated in the OLE of the COMPACT trial

\begin{tabular}{|c|c|c|c|c|}
\hline & \multicolumn{2}{|c|}{ All female subjects $(\mathrm{N}=76)$} & \multicolumn{2}{|c|}{ Females of childbearing age $(n=42)$} \\
\hline & $40 \mathrm{IU} / \mathrm{kg}(n=40)$ & $60 \mathrm{lU} / \mathrm{kg}(\mathrm{n}=36)$ & $40 \mathrm{IU} / \mathrm{kg}(\mathrm{n}=21)$ & $60 \mathrm{lU} / \mathrm{kg}(n=21)$ \\
\hline Age, mean (SD), y & $41.4(15.2)$ & $40.3(15.2)$ & $33.1(9.0)$ & $31.8(8.3)$ \\
\hline Weight, mean (SD), kg & $77.6(23.0)$ & $75.2(22.6)$ & $77.9(26.5)$ & $72.1(21.2)$ \\
\hline $\mathrm{BMI}$, mean (SD), $\mathrm{kg} / \mathrm{m}^{2}$ & $28.5(7.9)$ & $27.5(8.1)$ & $28.0(9.0)$ & $26.0(7.8)$ \\
\hline
\end{tabular}

OLE open-label extension 
Table 3 Attack frequency, rescue medication use, and attack severity in the female study population with HAE-C1INH

\begin{tabular}{llll}
\hline & All female subjects $\mathbf{n}=\mathbf{7 6})$ & $\begin{array}{l}\text { Female subjects of childbearing age } \\
\mathbf{( n = 4 2 )}\end{array}$ & $\begin{array}{l}\text { Overall study } \\
\text { population } \\
\mathbf{( N = 1 2 6 )}\end{array}$ \\
\hline $\begin{array}{l}\text { Number of attacks/month } \\
\text { Mean (SD) }\end{array}$ & $0.50(0.86)$ & $0.55(0.88)$ & $0.45(0.80)$ \\
$\quad \begin{array}{l}\text { Median (range) } \\
\text { Rescue medication use/month }\end{array}$ & $0.10(0.0-4.0)$ & $0.16(0.0-4.0)$ & $0.09(0.0-4.0)$ \\
$\quad \begin{array}{l}\text { Mean (SD) } \\
\text { Median (range) }\end{array}$ & $0.33(0.78)$ & $0.30(0.76)$ & $0.29(0.70)$ \\
Average severity of attacks ${ }^{\mathrm{a}}$ & $0.0(0.0-4.5)$ & $0.0(0.0-4.5)$ & $0.0(0.0-4.5)$ \\
$\quad \begin{array}{l}\text { Mean (SD) } \\
\text { Median (range) }\end{array}$ & $1.85(0.44)$ & $1.89(0.33)$ & $1.69(0.56)$ \\
\hline
\end{tabular}

HAE-C1INH hereditary angioedema due to C1-inhibitor deficiency

a $1=$ mild, $2=$ moderate, $3=$ severe

Table 4 C1-INH (SC) exposure and pregnancy outcomes in subjects with HAE-C1INH who became pregnant during treatment in the OLE

\begin{tabular}{|c|c|c|c|c|c|c|}
\hline Subject & Age (y) & C1-INH (SC) dose & Total exposure in the OLE & $\begin{array}{l}\text { Exposure } \\
\text { after last } \\
\text { menstruation }\end{array}$ & Delivery gestation time & Pregnancy outcome \\
\hline 1 & 19 & $60 \mathrm{IU} / \mathrm{kg}$ & 25.3 weeks (42 doses) & 8 weeks (15 doses) & Caesarean section at 39 weeks & Healthy baby $3.3 \mathrm{~kg}$ \\
\hline 2 & 27 & $60 \mathrm{IU} / \mathrm{kg}$ & 43.1 weeks ( 87 doses) & 5 weeks (10 doses) & Normal forceps at 40 weeks +5 days & Healthy baby $3.7 \mathrm{~kg}$ \\
\hline 3 & 32 & $40 \mathrm{IU} / \mathrm{kg}$ & 35.3 weeks (59 doses) & 5 weeks (10 doses) & $\begin{array}{c}\text { Caesarean section at } \\
39 \text { weeks }+3 \text { days }\end{array}$ & Healthy baby $2.9 \mathrm{~kg}$ \\
\hline 4 & 29 & $60 \mathrm{IU} / \mathrm{kg}$ & 27.9 weeks (55 doses) & 4 weeks ( 9 doses) & $\begin{array}{c}\text { Caesarean section at } \\
36 \text { weeks }+6 \text { days }\end{array}$ & Healthy baby $2.4 \mathrm{~kg}$ \\
\hline
\end{tabular}

HAE-C1INH hereditary angioedema due to C1-inhibitor deficiency, OLE open-label extension

sharp increase in the frequency of attacks (Fig. 2). Subject 1 experienced 1 attack between the last menstrual period and treatment discontinuation (8 weeks), but experienced 6 attacks over the 5 weeks between discontinuation of treatment and the last study visit. Subject 3 did not report any attacks between her last menstrual period and treatment discontinuation (5 weeks), but reported 7 attacks in the 8 weeks between treatment discontinuation and the last study visit (subjects did not use any other prophylactic medication during this time period). In both subjects, the rate of attacks between treatment discontinuation and the last study visit was higher than the pre-study rate.

\section{Safety}

The long-term safety profile of C1-INH (SC) in the female study population was consistent with that seen in the overall population (Table 5). Four women discontinued therapy due to adverse events (AEs), including headache (related to study drug), myalgia (related to study drug), arthralgia (not related to study drug), and acute myocardial infarction (not related to study drug). Of the 9 subjects in the trial who had serious AEs, 7 were female and reported 9 of the 12 serious AEs. None of the serious AEs were considered to be related to C1-INH (SC) therapy. The majority of AEs (81\%) in female subjects were mild, and 95\% of events resolved completely. As in the overall population, injection-site reactions (ISRs) were the most common $\mathrm{AE}$ among female subjects. The majority of ISRs were mild, none were severe, and all resolved. No subjects in the OLE had related thromboembolic events; no cases of anaphylaxis were reported; and no subjects had neutralizing anti-C1INH antibodies at baseline or post-baseline visits [18].

\section{Discussion}

Women with HAE-C1INH generally have a more severe disease course compared with men, presumably due to the role of estrogens in activating the kallikrein-kinin system [12-14]. Women of childbearing potential may be especially vulnerable, and indeed menstruation and pregnancy have been identified by female patients with HAE as potent triggers of attacks [6]. Various factors unique to women, including menses, ovulation, 


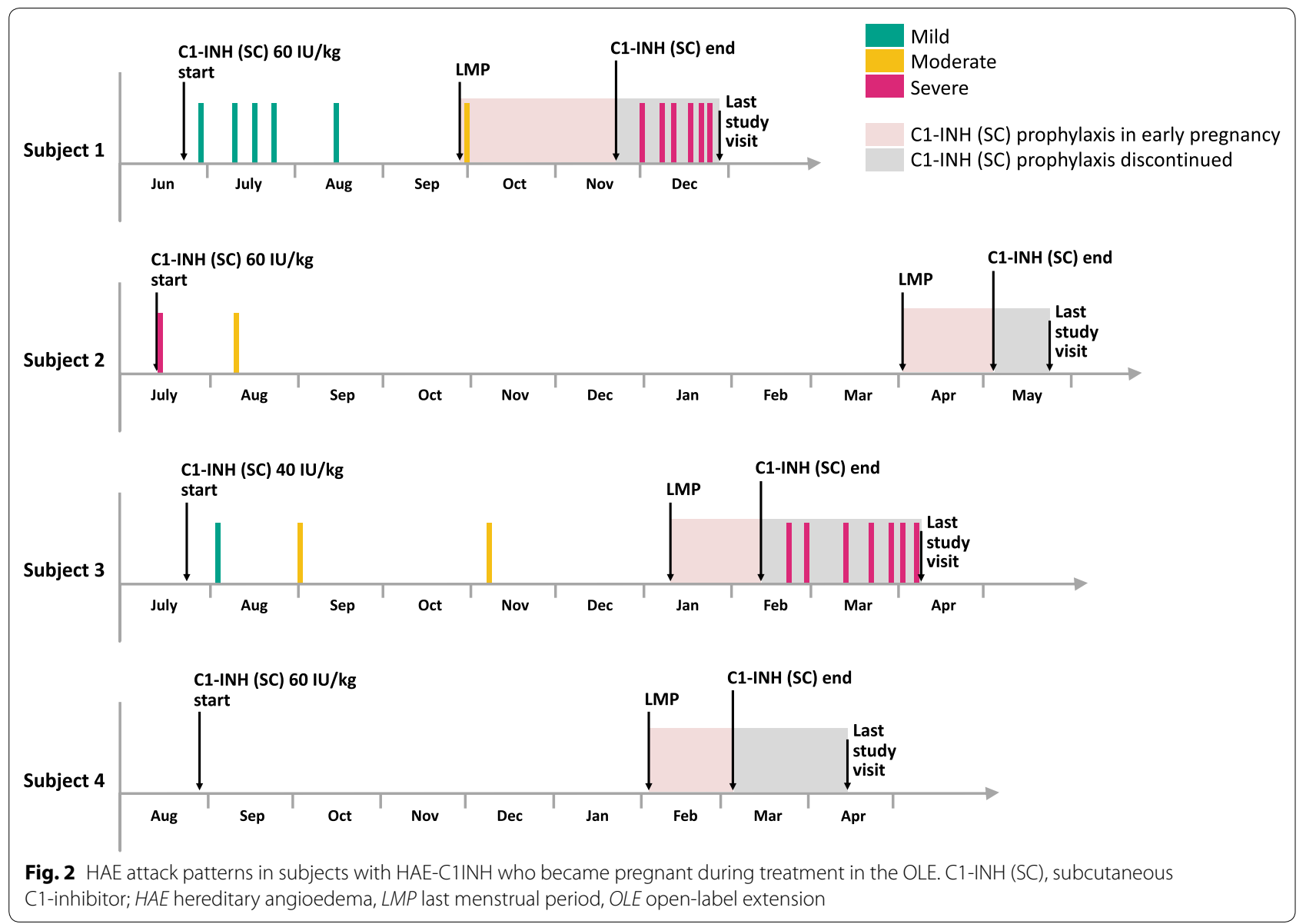

hormonal contraception, pregnancy, childbirth, breastfeeding, and menopause, lead to fluctuations in estrogen, which can influence HAE attack frequency and severity [5]. Although pregnancy has a variable effect on disease activity, many female patients with HAE experience an increase in attacks during pregnancy $[5,8]$. Therefore, many female patients with HAE-C1INH may benefit from prophylactic therapy designed to reduce the frequency and severity of HAE attacks. In this OLE of the pivotal COMPACT trial, C1-INH (SC) was highly effective as long-term prophylaxis in female subjects with HAE-C1INH, including those of childbearing age. Overall, $91 \%$ of female subjects had $50 \%$ or greater reduction in attacks relative to the pre-study period and $82 \%$ had their attack rate reduced to $<1$ attack/4 weeks. Among female subjects in the OLE, the median number of attacks per month was $0.10(\sim 1$ attack/year), with a $96 \%$ median reduction in attacks relative to the prestudy period. C1-INH (SC) was also well tolerated-mild, localized ISRs were the most common AEs.

Prophylactic treatment of HAE in women, especially those of childbearing age, presents some unique challenges. Women of childbearing age may plan a pregnancy or become pregnant unintentionally during HAE prophylactic therapy. Use of an effective therapy that has been proven to be safe during pregnancy may help women with HAE-C1INH in planning a pregnancy and facilitate continuity of HAE management before, during, and after pregnancy.

In current international guidelines, pdC1-INH is the preferred option for long-term prophylaxis in women during pregnancy and lactation $[15,20]$. This recommendation is based on several reports documenting the efficacy and safety of pdC1-INH as prophylaxis and acute treatment during pregnancy in women with HAE-C1INH [7-9, 21, 22]. Attenuated androgens are contraindicated in pregnancy and are associated with fetal abnormalities [15, 23]. A review of women exposed to danazol during pregnancy $(\mathrm{N}=129$ reported pregnancies) showed that of 94 completed pregnancies, 12 resulted in miscarriage, and 23 resulted in the birth of virilized females [23]. Other congenital abnormalities were also reported.

Attenuated androgens are also associated with side effects that can impact conception planning. In a study of patients with HAE-C1INH $(\mathrm{N}=118)$ that included 58 
Table 5 Adverse event (AE) profile of C1-INH (SC) in female subjects

\begin{tabular}{|c|c|c|c|}
\hline Adverse events & All female subjects $(n=76)$ & $\begin{array}{l}\text { Females of childbearing age } \\
(n=42)\end{array}$ & $\begin{array}{l}\text { Overall study } \\
\text { population } \\
(\mathrm{N}=126)\end{array}$ \\
\hline & No. of events & & \\
\hline Any AE & 911 & 568 & 1811 \\
\hline AEs leading to discontinuation & 4 & 2 & 4 \\
\hline Related AEs & 505 & 348 & 1257 \\
\hline Serious AEs & 9 & 3 & 12 \\
\hline Related serious AEs & 0 & 0 & 0 \\
\hline \multicolumn{4}{|l|}{ Severity } \\
\hline Mild & 734 & 473 & 1572 \\
\hline Moderate & 161 & 87 & 218 \\
\hline Severe & 16 & 8 & 21 \\
\hline \multicolumn{4}{|l|}{ Outcome } \\
\hline Recovered/resolved & 869 & 548 & 1758 \\
\hline Solicited AEs (injection-site reactions & & & 1251 \\
\hline \multicolumn{4}{|l|}{ Severity } \\
\hline Mild & 488 & 339 & 1234 \\
\hline Moderate & 9 & 5 & 17 \\
\hline Severe & 0 & 0 & 0 \\
\hline \multicolumn{4}{|l|}{ Outcome } \\
\hline Recovered/resolved & 497 & 344 & 1251 \\
\hline
\end{tabular}

C1-INH (SC) subcutaneous C1-inhibitor

women treated with danazol ( 2 months to 30 years), the most frequent clinical adverse effects were weight gain, menstrual irregularities (including amenorrhea in 16 of 38 premenopausal women), and virilization [24].

In our study protocol, female subjects of childbearing potential with HAE-C1INH were required to use reliable contraception or be sexually abstinent during the trial. Nevertheless, 4 subjects became pregnant and were exposed to C1-INH (SC) for 4 to 8 weeks after their last menstrual period (i.e., the first trimester of pregnancy). During this period of prophylaxis in early pregnancy, only a single HAE attack was reported. HAE attacks during pregnancy may be especially challenging for women with HAE-C1INH. Abdominal attacks are often associated with nausea, vomiting, and diarrhea [25], which may compound pregnancy-associated gastrointestinal symptoms ("morning sickness"). Abdominal attacks that occur later in pregnancy may be mistaken for labor symptoms. Prevention of HAE attacks with prophylactic therapy may help improve quality of life during pregnancy.

\section{Conclusions}

C1-INH (SC) was demonstrated to be safe and effective as long-term prophylaxis in women with HAE-C1INH. The 4 women who became pregnant during the trial and were exposed to C1-INH (SC) during the first trimester of pregnancy when the risk of teratogenic effects is greatest, delivered healthy babies with no congenital abnormalities. Although C1-INH replacement therapy has been in clinical use for 40 years and its safety and efficacy profile in women with HAE are well established, additional data on the safety of C1-INH (SC) prophylaxis during pregnancy and lactation are needed.

\section{Abbreviations}

C1 INH: C1 inhibitor; COMPACT: Clinical Study for Optimal Management of Preventing Angioedema with Low-Volume Subcutaneous C1-Inhibitor Replacement Therapy; EAACl: European Academy of Allergy and Clinical Immunology; HAE: Hereditary angioedema; HAE-C1INH: Hereditary angioedema due to $\mathrm{C} 1$ inhibitor deficiency; HMWK: High-molecular-weight kininogen; HRT: Hormone replacement therapy; Hsp90: Heat shock protein 90; IL: Interleukin; OLE: Open-label extension; pd: Plasma derived; SC:

Subcutaneous; TNF: Tumor necrosis factor; TP: Treatment period; WAO: World Allergy Organization.

\section{Acknowledgements}

Editorial and medical writing assistance was provided by NCF Health, LLC, and funded by CSL Behring.

Authors' contributions

All authors contributed to the concept of the study, data analysis, and reviewed each draft. All authors read and approved the final manuscript.

Funding

The phase III COMPACT study was funded by CSL Behring, Marburg, Germany. 


\section{Availability of data and materials}

The datasets used and/or analysed during the current study are available from the corresponding author on reasonable request.

\section{Ethics approval and consent to participate}

Study Protocol and amendments were approved by independent ethics committees or institutional review boards at all participating centers prior to study commencement. All patients, or their legal guardians, provided written informed consent.

\section{Consent for publication}

\section{Not applicable.}

\section{Competing interests}

D. Levy has served on the speaker's bureau, as a consultant, on a steering committee, and as a clinical investigator for CSL Behring; consultant for BioCryst; and speaker for Takeda. H. Farkas received institutional support for a clinical trial for this study from CSL Behring; advisory board/consultancy fees and/or speaker's honoraria from BioCryst, CSL Behring, Shire, and Sobi (Swedish Orphan Biovitrum); and travel support from CSL Behring. M. Riedl reports grant support from CSL Behring during the conduct of the study and has received research grants from BioCryst, CSL Behring, Dyax, lonis Pharmaceuticals, Pharming Technologies, and Shire; has served as a consultant and/or speaker for Adverum Biotechnologies, Alnylam Pharmaceuticals, Arrowhead Pharmaceuticals, BioCryst, CSL Behring, Dyax, Global Blood Therapeutics, lonis Pharmaceuticals, KalVista Pharmaceuticals, Pharming Technologies, Salix Pharmaceuticals, and Shire; and is an uncompensated advisory board member for the US Hereditary Angioedema Association, outside the submitted work.F. Hsu reports serving as a consultant for BioCryst; serving as a speaker for CSL Behring, Pharming Technologies BV, and Takeda Pharmaceutical Company Ltd; and performing contracted research for Hoffman-La Roche. J.P. Brooks declares that he has no competing interests. M. Cicardi received grants from Shire and personal fees from Alnylam, BioCryst, CSL Behring, Dyax, KalVista, Pharming Technologies, Shire, Sobi (Swedish Orphan Biovitrum), and ViroPharma. H. Feuersenger and I. Pragst are employees of CSL Behring. A. Reshef reports grant support from CSL Behring during the conduct of the study and has received grant support from Pharming.

\section{Author details}

${ }^{1}$ University of California-Irvine, Orange, 705 W La Veta Avenue, Suite 101, Orange, CA 92868, USA. ${ }^{2}$ Hungarian Angioedema Reference Center, Third Department of Internal Medicine, Semmelweis University, Budapest, Hungary. ${ }^{3}$ School of Medicine, University of California-San Diego, La Jolla, CA, USA.

${ }^{4}$ Yale University School of Medicine, New Haven, CT, USA. ${ }^{5}$ IRCCS-ICS Maugeri Milano, University of Milan, Milan, Italy. ${ }^{6}$ CSL Behring, Marburg, Germany. ${ }^{7}$ Allergy, Immunology and Angioedema Center, Barzilai Medical Center, Ashkelon, Israel.

Received: 16 December 2019 Accepted: 27 January 2020 Published online: 04 February 2020

\section{References}

1. Agostoni A, Aygören-Pürsün E, Binkley KE, Blanch A, Bork K, Bouillet LC, et al. Hereditary and acquired angioedema: problems and progress: proceedings of the third C1 esterase inhibitor deficiency workshop and beyond. J Allergy Clin Immunol. 2004;114:S51-131.

2. Bork K, Meng G, Staubach P, Hardt J. Hereditary angioedema: new findings concerning symptoms, affected organs, and course. Am J Med. 2006;119:267-74.

3. Agostoni A, Cicardi M. Hereditary and acquired C1-inhibitor deficiency: biological and clinical characteristics in 235 patients. Medicine (Baltimore). 1992;71:206-15.

4. Bouillet L, Launay D, Fain O, Boccon-Gibod I, Laurent J, Martin L, et al. French National Reference Center for Hereditary Angioedema (CREAK). Hereditary angioedema with C1 inhibitor deficiency: clinical presentation and quality of life of 193 French patients. Ann Allergy Asthma Immunol. 2013;111:290-4.
5. Bouillet L, Longhurst H, Boccon-Gibod I, Bork K, Bucher C, Bygum A, et al. Disease expression in women with hereditary angioedema. Am J Obstet Gynecol. 2008;199:484.e1-4.

6. Zotter Z, Csuka D, Szabó E, Czaller I, Nébenführer Z, Temesszentandrási $\mathrm{G}$, et al. The influence of trigger factors on hereditary angioedema due to C1-inhibitor deficiency. Orphanet J Rare Dis. 2014;9:44.

7. Czaller I, Visy B, Csuka D, Füst G, Tóth F, Farkas H. The natural history of hereditary angioedema and the impact of treatment with human C1-inhibitor concentrate during pregnancy: a long-term survey. Eur J Obstet Gynecol Reprod Biol. 2010;152:44-9.

8. Martinez-Saguer I, Rusicke E, Aygören-Pürsün E, Heller C, Klingebiel T, Kreuz W. Characterization of acute hereditary angioedema attacks during pregnancy and breast-feeding and their treatment with C1 inhibitor concentrate. Am J Obstet Gynecol. 2010;203:131.e1.

9. González-Quevedo T, Larco Jl, Marcos C, Guilarte M, Baeza ML, Cimbollek S, et al. Management of pregnancy and delivery in patients with hereditary angioedema due to C1 inhibitor deficiency. J Investig Allergol Clin Immunol. 2016;26:161-7.

10. Chinniah N, Katelaris CH. Hereditary angioedema and pregnancy. Aust N Z J Obstet Gynaecol. 2009;49:2-5.

11. Bork K, Fischer B, Dewald G. Recurrent episodes of skin angioedema and severe attacks of abdominal pain induced by oral contraceptives or hormone replacement therapy. Am J Med. 2003;114:294-8.

12. Joseph K, Tholanikunnel BG, Kaplan AP. Cytokine and estrogen stimulation of endothelial cells augments activation of the prekallikrein-high molecular weight kininogen complex: implications for hereditary angioedema. J Allergy Clin Immunol. 2017;140:170-6.

13. Colman RW. Surface-mediated defense reactions. The plasma contact activation system. J Clin Invest. 1984;73:1249-53.

14. Madeddu P, Emanueli C, Song Q, Varoni MV, Demontis MP, Anania V, et al. Regulation of bradykinin B2-receptor expression by oestrogen. $\mathrm{Br}$ J Pharmacol. 1997;121:1763-9.

15. Maurer M, Magerl M, Ansotegui I, Aygören-Pürsün E, Betschel S, Bork $\mathrm{K}$, et al. The international WAO/EAACI guideline for the management of hereditary angioedema-the 2017 revision and update. Allergy. 2018;73:1575-96.

16. US Food and Drug Administration. FDA approves first subcutaneous C1 esterase inhibitor to treat rare genetic disorder. June 22, 2017: Press release. https://www.fda.gov/news-events/press-announcements/ fda-approves-first-subcutaneous-c1-esterase-inhibitor-treat-rare-genet ic-disease. Accessed 14 June 2019.

17. Longhurst H, Cicardi M, Craig T, Bork K, Grattan C, Baker J, COMPACT Investigators, et al. Prevention of hereditary angioedema attacks with a subcutaneous C1 inhibitor. N Engl J Med. 2017;376:1131-40.

18. Craig T, Zuraw B, Longhurst H, Cicardi M, Bork K, Grattan C, COMPACT Investigators, et al. Long-term outcomes with subcutaneous C1-inhibitor replacement therapy for prevention of hereditary angioedema attacks. J Allergy Clin Immunol Pract. 2019;7:1793-802.

19. Riedl MA, Jacobs J, Li HH, Levy D, Chiao J, Feuersenger H, et al. Efficacy of prophylaxis with subcutaneous C1-esterase inhibitor (C1 INH [SC]) in female patients with hereditary angioedema: subgroup analysis from the COMPACT study. Presented at, EAACI Congress; May 26-30, 2018. Germany: Munich; 2018.

20. Caballero T, Farkas H, Bouillet L, Bowen T, Gompel A, Fagerberg C, et al. C-1-INH Deficiency Working Group International consensus and practical guidelines on the gynecologic and obstetric management of female patients with hereditary angioedema caused by C1 inhibitor deficiency. J Allergy Clin Immunol. 2012;129:308-20.

21. Baker JW, Sheffer A, Christensen J, Hurewitz D, Lazar R, Kalfus I, et al. Cinryze ${ }^{\mathrm{TM}}$ replacement therapy in hereditary angioedema and pregnancy. J Allergy Clin Immunol. 2009;123:S106.

22. Bouillet L, Boccon-Gibod I, Pagnier A, Gompel A, Floccard B, Laurent J, et al. Hereditary angioedema: follow up of C1INH deficiency (Type I-II) patients with long term prophylaxis: (COBRA registry). Allergy EAACl. 2016;71:410.

23. Brunskill PJ. The effects of fetal exposure to danazol. Br J Obstet Gynaecol. 1992;99:212-5

24. Bork K, Bygum A, Hardt J. Benefits and risks of danazol in hereditary angioedema: a long-term survey of 118 patients. Ann Allergy Asthma Immunol. 2008;100:153-61. 
25. Bork K, Staubach P, Eckardt AJ, Hardt J. Symptoms, course, and complications of abdominal attacks in hereditary angioedema due to C1 inhibitor deficiency. Am J Gastroenterol. 2006;101:619-27.

\section{Publisher's Note}

Springer Nature remains neutral with regard to jurisdictional claims in published maps and institutional affiliations.

Ready to submit your research? Choose BMC and benefit from:

- fast, convenient online submission

- thorough peer review by experienced researchers in your field

- rapid publication on acceptance

- support for research data, including large and complex data types

- gold Open Access which fosters wider collaboration and increased citations

- maximum visibility for your research: over $100 \mathrm{M}$ website views per year

At $\mathrm{BMC}$, research is always in progress.

Learn more biomedcentral.com/submissions 